\title{
Ecos de Angicos: temas freireanos e a pedagogia atual
}

\author{
Danilo R. Streck * \\ http://dx.doi.org/10.1590/0103-7307201407505
}

\section{Resumo}

O texto propõe-se a refletir sobre o legado de Paulo Freire e a sua contribuição para a educação contemporânea. São identificados quatro elementos da pedagogia freireana que são de especial relevância na pedagogia atual: a) a recriação e o cultivo

* Universidade do Vale do Rio Sinos (UNISINOS), São Leopoldo, RS, Brasil. dstreck@unisinos.br do pensamento utópico; b) a radicalidade como base da ação ético-pedagógica; c) o diálogo como princípio metodológico; d) a libertação da pedagogia para uma nova rigorosidade. Os "ecos de Angicos" ajudam a articular diferentes posições, não temendo o trabalho nas fronteiras das áreas de conhecimento e as perspectivas epistemológicas; ao mesmo tempo, desafiam a ir às raízes e compreender as condições sociais nas quais as práticas educativas estão inseridas e onde são criadas as condições para a emergência dos "inéditos viáveis".

\section{Palavras-chave}

Pedagogia freireana, pensamento utópico, pedagogia radical, diálogo, rigorosidade metodológica. 


\title{
Echoes from Angicos: \\ Freirean Themes and the today's pedagogy
}

\begin{abstract}
The article identifies four elements in Freirean pedagogy which are of special relevance for present-day pedagogy: a) the rebirth and cultivation of utopian thinking; b) radicalism as foundation for pedagogical-ethical action; c) dialogue as a methodological principle; e) the liberation of pedagogy. The "echoes" of Angicos help to articulate different positions, not renouncing to work in the frontiers of different fields of knowledge and epistemological perspectives; at the same time, they challenge the need to understand the social conditions in which educational practices are rooted and in which are created the conditions for the emergence of new feasibilities.
\end{abstract}

Keywords

Freirean pedagogy, utopian thinking, radical pedagogy, dialogue, methodological rigorousness. 


\section{Os ecos de Angicos}

Os anos que nos separam da morte de Paulo Freire (1997) são um espaço de tempo curto para se efetuar um balanço mais rigoroso de sua contribuição para a educação. Talvez por isso, não raro nos deparamos com a polêmica dos "contra" e dos "a favor". Os primeiros, argumentando que Paulo Freire deveria ser esquecido, porque existem propostas pedagógicas mais atuais e relevantes; e o segundo grupo, reverenciando-o como alguém que se encontra fora e acima das críticas. Tanto uma como a outra postura são pouco produtivas para a educação, além de contrárias ao próprio pensamento de Paulo Freire. Ele tinha plena consciência da transitoriedade daquilo que se faz e pensa, mas, paradoxalmente, era capaz de ver, nessa mesma transitoriedade, os sinais de permanência e de transcendência.

Parece mais adequado reconhecer que nos deparamos, hoje, com múltiplos Freires $^{1}$ e que não faz sentido colocar-se como guardião do que supostamente poderia ser o verdadeiro Freire. Ele tinha a virtude de reconhecer as inevitáveis contradições em sua própria vida, pelo simples fato de essas fazerem parte da sociedade na qual se vive. Por exemplo, muitos meninos pobres do Recife não tiveram as oportunidades que foram criadas por pessoas de sua família e pelo diretor do Colégio Oswaldo Cruz para que ele estudasse. Mas ele nunca entendeu isso como um direito que the permitisse esquecer que as condições de vida em nossa sociedade são desiguais. A coerência que pregava, sem moralismos ou fatalismos, tinha a ver com um posicionamento de denúncia dessas condições e de anúncio, na práxis (palavra-ação), de novas possibilidades de construir a existência individual e coletiva.

O reconhecimento do caráter historicamente situado de sua obra está manifesto também no fato de que ele soube recriar-se, na prática e na teoria, dentro dos movimentos da história. Sua pedagogia do oprimido virou pedagogia da esperança, pedagogia da autonomia, pedagogia da indignação, entre outras nominadas por ele mesmo ou por quem nele se inspirou para mostrar um outro lado ou uma outra dimensão da prática educativa voltada para o "ser mais". o próprio "ser mais" nunca designou uma determinada forma para o ser humano ou os limites do que este poderia ser, mas apontava para a incompletude da vida como espaço de realização. Não há, portanto, razão para fixar Paulo Freire em determinado momento da história ou vinculá-lo de forma determinista a uma matriz teórica ou a algum campo da prática.

Em diálogos sobre a obra de Paulo Freire, é comum que alguém se identifique mais com a

1. Ver Rosa Maria Torres, Os múltiplos Paulo Freire. 
Pedagogia do oprimido (1981), outro já vê em Política e educação (1995b) ou em Cartas a Cristina (1994) a grande inspiração para a sua prática. A enorme receptividade de Pedagogia da autonomia (1996) indica que muitos estudantes e educadores encontram, hoje, nesse pequeno livro, as lições para o seu trabalho e para a sua vida. Alguns veem em Paulo Freire o inspirador da Educação Popular, outros buscam nele lições como gestores de sistemas de ensino, a partir de sua experiência à frente da Secretaria de Educação na cidade de São Paulo; ainda outros reconhecem nele elementos para a construção de uma filosofia da educação ou, simplesmente, apreciam seu jeito de ser e de lidar com a vida e as coisas da educação.

Para alguns, o nome Paulo Freire talvez tenha virado marca, uma espécie de grife para garantir credibilidade ou legitimidade, desde nome de escolas a citações de trabalhos acadêmicos. 0 fato de ter sido declarado Patrono da Educação Brasileira (Lei n. 12.612, de 13 de abril de 2012), por um lado, é um justo reconhecimento; por outro lado, insere o nome em disputas de pouco conteúdo político-pedagógico. Não obstante, para a grande maioria que se ocupa com seu pensamento e sua obra, Freire simboliza a possibilidade de se pensar o que ele chamava "inéditos viáveis". Essa busca de "inéditos viáveis" ou do "sonho possível" pode acontecer no cotidiano da sala de aula, na gestão de escolas ou de sistema de ensino, no trabalho com saúde pública, em movimentos sociais e em qualquer lugar onde se aceita a premissa de que o futuro não precisa ser a repetição do presente e que a educação tem um papel em projetar e construir este outro futuro. A educação não tem o poder imediato da economia, do voto ou das armas do exército. Mas paradoxalmente, para Freire, é na sua fraqueza que reside sua força, assim como a fraqueza dos oprimidos contém o gérmen da transformação. Segundo ele, "se o poder econômico e político dos poderosos desaloja os fracos dos mínimos espaços de sobrevivência, não é porque assim deva ser; é preciso que a fraqueza dos fracos se torne uma força capaz de inaugurar a justiça”" (Freire, 1995a, p. 23).

É a palavra autêntica, unida à ação, que tem o poder mágico de transformação. Thiago de Mello, referindo-se ao homem que aprende a ler a palavra e ler o mundo, disse isso de uma forma muito bela em sua "Canção para os fonemas da alegria":

... porque unindo pedaços de palavras aos poucos vai unindo argila e orvalho, tristeza e pão, cambão e beija-flor, 
e acaba por unir a própria vida

no seu peito partida e repartida

quando afinal descobre num clarão

que o mundo é seu também...

(Freire, 1980, p. 27).

Há, em suas afirmações, uma obviedade inquietante e provocadora que desafia a querer saber mais. Ele tinha consciência deste seu papel de "peregrino do óbvio", como ele mesmo dizia de si. Mas esta simplicidade nada tem a ver com o fácil ou superficial. Uma vasculhada em sua biblioteca pessoal no Instituto Paulo Freire (São Paulo) surpreende não apenas pela quantidade, diversidade e qualidade, mas também pelo número de anotações à margem das obras. Um exemplo desse óbvio é quando ele diz, em Pedagogia do oprimido, que nenhuma ordem autoritária sobreviveria, se todos começassem a fazer esta pergunta básica: “Por quê?”. É simples, mas nada fácil. Já outros veem nesse seu jeito de fazer pedagogia a falta de rigor científico e acadêmico, talvez sem perceber que ele propõe outro tipo de rigorosidade.

Entendo que sua obra é uma espécie de "sombra de mangueira”, conforme o título de um de seus livros, onde pessoas se encontram para recarregar energias, buscar inspiração e renovar suas ideias e práticas. Mas essa sombra tem suas fronteiras, e sua eventual pretensão de universalidade não está em abarcar tudo, mas em afirmar a relevância de determinado tipo de prática e de reflexão para o mundo em que vivemos. Rosa Maria Torres (2001, p. 242) expressou de uma maneira muito feliz o que talvez seja o grande legado de Paulo Freire:

Pouco importa se uns entenderam Freire melhor do que outros, se existiram os que compreenderam realmente o seu pensamento ou não. A maior contribuição de Paulo Freire talvez seja ter conseguido comunicar-se e conectar-se com a fibra mais amorosa e genuína de muitas pessoas - babel de idades, raças, credos, posições econômicas, sociais e ideológicas, níveis educativos, profissões e ocupações - ajudando-as a saberem que existe algo chamado educação e algo chamado pobreza/marginalização/opressão, que existe uma relação entre ambas, que tal relação pode ser tanto de cumplicidade quanto de ruptura, útil tanto para oprimir quanto para libertar. 
O legado de Paulo Freire se ramifica, portanto, em vários campos da reflexão teórica e da prática. Isso se evidencia nas muitas coletâneas sobre sua obra, como a organizada por ocasião dos 30 anos da publicação da Pedagogia do oprimido no Brasil (Araújo Freire, 2001), o Dicionário Paulo Freire ${ }^{2}$ (Streck; Redin; Zitkoski, 2010) ou sobre temas específicos, como a educação para a justiça social (Torres Novoa; Noguera, 2008). Por ocasião dos 50 anos (1963-2013), recoloca-se a pergunta pela atualidade de Paulo Freire. Talvez haja um problema na própria colocação dessa pergunta. A questão que importa não é se Paulo Freire continua atual, o que num sentido mais estrito é impossível, mas de que forma ele nos ajuda a sermos habitantes de nosso tempo. Ao discutir o uso da televisão na sala de aula, ele diz o seguinte: “Tenho a impressão de que o melhor que posso dizer, no começo de minha reflexão, em torno desse problema, é: uma das coisas mais lastimáveis para um ser humano é ele não pertencer a seu tempo. É se sentir, assim, um exilado de seu tempo." (Freire; Guimarães, 1984, p. 14). A questão que cabe é o que significa não ser um exilado de um tempo - frase dita no diálogo acima com Sérgio Guimarães - quando, além da televisão, temos amplo acesso à Internet, quando as tecnologias digitais colocam à disposição formas de interação e instrumentos de informação inconcebíveis há duas décadas? Diante da pergunta de onde estaria a maior contribuição de Paulo Freire para a educação contemporânea, também as respostas serão múltiplas, dependendo do Paulo Freire que se tomar como companheiro. Para uns será o Paulo Freire revolucionário; para outros, o educador dialógico; para outros, o pensador multidisciplinar, entre muitos possíveis. 0 que segue é um exercício que carrega as marcas de quem fez a escolha e não tem a pretensão de responder pela totalidade da obra de Freire. Uma das grandes lições de Freire está, a meu ver, no fato de ele se colocar permanentemente como testemunho do ato de conhecer, um conhecer que é também sempre um pronunciar o mundo em que se vive. 0 tão falado diálogo não é, para Freire, um método entre outros, mas uma postura diante do mundo, dos outros e do próprio conhecimento. Uma postura de quem sabe que sabe, mas que, em sabendo, sabe que tem ainda, e sempre, muito a saber. Dentro dessa perspectiva, identifico pelo menos quatro lugares onde o pensamento de Paulo Freire é especialmente relevante hoje: a) na recriação e no cultivo do pensamento utópico; b) na radicalidade como base da ação ético-pedagógica; c) no diálogo como princí-

2. Publicado em inglês, com o título Paulo Freire Encyclopedia. pio metodológico; d) na libertação da pedagogia para uma nova rigorosidade. 


\section{0 utópico}

A utopia, para Freire, não consiste num retorno a um passado ideal ou na dicotomização entre um estado de perfeição e uma condição presente à qual estamos fatalisticamente presos. Ele traduz essa tensão inerente à utopia neste parágrafo que, pela expressividade, transcrevo na íntegra:

Utópico para mim não é o irrealizável, não é idealismo. Utopia é a dialetização nos atos de denunciar e anunciar. 0 ato de denunciar a estrutura desumanizante, e o ato de anunciar a estrutura humanizadora. Por essa razão é também compromisso histórico. A utopia exige conhecer criticamente. É um ato de conhecimento. Eu não posso denunciar a estrutura desumanizante se não a penetro para conhecê-la. Não posso anunciar se não a conheço. Mas entre 0 anúncio e a realização do anúncio há algo que deve ser enfatizado e que é que o anúncio não é o anúncio de um projeto, mas é o anúncio de um anteprojeto. Porque o anteprojeto se faz projeto na práxis histórica. Assim sendo, entre o anteprojeto e o momento da realização ou concretização do projeto há um momento que se chama histórico. É exatamente a história que nós temos que criar com nossas mãos e temos que fazer. É o tempo das transformações que temos que realizar. É o tempo de meu compromisso histórico. Por essa razão somente os utópicos - e enquanto utópicos revolucionários - (quem foi Marx senão um utópico, quem foi Guevara senão um utópico) podem ser proféticos e podem ser esperançosos (Torres Novoa, 1977, p. 112). ${ }^{3}$

O “inédito viável” irrompe no tempo cronológico e se faz história. Esse tempo histórico, por um lado, implica condicionamento e, por outro, possibilidade. É na tensão entre essas duas condições da existência humana que se realiza a autonomia, o tema central de seu último livro, Pedagogia da autonomia. A primeira dessas condições aponta para os limites dentro dos quais a vida de cada um e cada uma se desenvolve. Paulo Freire, como sabemos, faz distinção entre condicionamento e determinação. Se fôssemos determinados, nosso tempo não seria um tempo de história, o qual, pelo contrário, é um tempo de possibilidades, porque o próprio limite não é sentido como uma fatalidade, mas como um momento na realização do "ser mais". Diz ele:

3. "Conscientizar para liberar (Nociones sobre la palabra conscienización). Originalmente foi uma conferência de Freire em Cuernavaca (México)", no Centro Intercultural de Documentación (CIDOC). 
o futuro não é uma província histórica mais além do hoje à espera de que lá cheguemos um dia e façamos a operação de acrescentar este amanhã já feito ao hoje, tornando-se velho e superado. [...] Numa perspectiva verdadeiramente dialética o sonho que nos move é uma possibilidade por que devo lutar para que se realize (Freire, 1994, p. 192, grifos do autor).

O que faz com que os condicionamentos sejam sentidos como situação-limite é a possibilidade humana de transcender. Não no sentido religioso da ligação com uma força sagrada, embora Freire não descarte essa possibilidade para a sua própria existência, mas transcendência no sentido de uma não aderência ao cotidiano, ao mundo. Homens e mulheres são seres que podem estar com o mundo e não só no mundo, podem tomar distância e, por meio desse movimento, identificar as possibilidades de mudança. Leonardo Boff escreve que

a transcendência não é apenas um tema recorrente em toda a obra de Paulo Freire. É a sua pressuposição fundamental. Falar em opressão-libertação-liberdade-esperança implica compreender o ser humano como um ser de transcendência, quer dizer, que pode romper as cadeias, inaugurar uma prática inovadora e esperar por um mundo possível e não ensaiado (Boff, 2010, p. 407).

Não havendo uma maneira predeterminada de estar no mundo, abre-se um amplo espaço para o que Freire (1992, p. 91) chama de "sonho estratégico". Sonhar como ato político e como forma de estar sendo homens e mulheres não apenas permite, mas exige esse espaço de criação e reinvenção da práxis. Considerando esta característica de abertura do projeto político-pedagógico freireano, Balduíno Andreola (2000, p. 24) propõe que, a partir de Freire, temos a possibilidade ímpar de desenvolver uma "pedagogia das grandes convergências" ou, como Andreola tem sugerido em recentes diálogos, das "grandes urgências".

A pedagogia de Paulo Freire, portanto, coloca-se contra os discursos fatalistas que proclamam o fim da história ou o fim das utopias, um mundo de seres "adaptados" ao que existe como destino predefinido. Um das contribuições de Freire para a educação contemporânea é ajudar a conceber a prática educativa como a "prática da liberdade”, no sentido da emancipação individual e coletiva. Não é por acaso que 
vemos a pedagogia freireana presente em alguns dos grandes debates que se travam hoje em dia. Basta citar alguns exemplos.

Um deles diz respeito à tensão entre diversidade e igualdade. Para Freire, trata-se de manter dialeticamente "a diversidade na unidade". Reconhece que o discurso da diversidade pode facilmente levar à fragmentação, favorecendo a continuidade da opressão por meio da divisão. “O dividir para dominar” é para ele uma das características da "ação antidialógica”. Em suas palavras:

Quanto mais se pulverize a totalidade de uma área em "comunidades locais", nos trabalhos de "desenvolvimento de comunidade", sem que estas comunidades sejam estudadas como totalidades em si, que são parcialidades de outra totalidade (área, região, etc.) que, por sua vez, é parcialidade de uma totalidade maior (o país, como parcialidade da totalidade continental) tanto mais se intensifica a alienação. E, quanto mais alienados, mais fácil dividi-los e mantê-los divididos (Freire, 1981, p. 166, grifos do autor).

Da mesma forma, ele nega que o devir histórico possa ser reduzido a uma só causa. Existem classes sociais, com interesses distintos, às vezes antagônicos, mas existem também as lutas das mulheres, dos negros, dos povos originários, das pessoas com deficiências que não podem simplesmente ser subsumidas dentro de uma única luta. A sociedade por ele desenhada mantém em tensão dialética os valores históricos da luta pela igualdade e as necessárias conquistas das diferenças.

Outro lugar onde se verifica crescente contribuição de Paulo Freire é na educação ecológica. Trata-se de restabelecer a vinculação existente entre comprometimento social e o mundo no qual esta ação humana se desenvolve. Ele insiste que, para os seres humanos, diferente dos animais, o mundo não é apenas "suporte”, mas já é, desde sempre, um mundo transpassado pela cultura. A própria natureza, desde que nominada pelo ser humano, é o resultado de uma ação cultural. A ação libertadora e transformadora de homens e mulheres por uma sociedade mais justa, portanto, não pode ser separada da ação pelo mundo da natureza, que garante a própria possibilidade de humanização. Embora o conceito de ecologia apareça apenas em seus últimos escritos, toda a sua obra é marcada pelo profundo amor ao ser humano e ao mundo em que vive. (Calloni, 2010; Gadotti, 2000). 


\section{A radicalidade}

Quando Paulo Freire define a si mesmo como radical, o faz contrapondo a radicalidade ao sectarismo. O sectário, de direita ou de esquerda, é alguém que se pretende proprietário da história. “A sectarização, diz ele, tem uma matriz preponderantemente emocional e acrítica. É arrogante, antidialogal e por isso anticomunicativa. É reacionária, seja assumida por direitista, que para nós é um 'sectário’ de nascença, ou esquerdista. O sectário nada cria porque não ama” (Freire, 1980, p. 50).

0 radical, por outro lado, é alguém que se sabe parte de uma história que ele, ao mesmo tempo, sofre e constrói. “A radicalização, que implica no enraizamento que o homem faz na opção que fez, é positiva, porque preponderantemente crítica. Porque crítica e amorosa, humilde e comunicativa” (Freire, 1980, p. 50). Nessa definição há dois momentos complementares. 0 primeiro deles é a própria opção, o que ainda não significa muito, uma vez que não é possível existir na história sem fazer opções. 0 próprio fato de não fazer opção é também uma opção. 0 novo - este é o segundo momento consiste no enraizamento na opção já feita, ou seja, na busca da raiz dessa opção. Nesse processo, pode-se descobrir, por exemplo, como uma opção partidária ou, como professor, uma escolha teórica e metodológica se deu por pressão de um grupo, pela falta de conhecimento de alternativas ou por outras razões que impedem o enraizamento.

A radicalidade permite a vivência de uma atitude aberta na qual as diferenças e as próprias contradições formam uma síntese num novo patamar de existência. As pessoas verdadeiramente radicais, no sentido de Freire, com certeza são raras, por isso parecem mais plenamente humanas que a maioria de nós. Na história, podemos pensar em figuras como Ghandi, Martin Luther King, Nelson Mandela ou Hélder Câmara. São pessoas cuja universalidade está na constante busca da "raiz", onde as diferenças partidárias ou ideológicas são percebidas como menores. Trata-se, emprestando uma linguagem da teologia, de não confundir as últimas coisas com as penúltimas, mantendo viva a tensão entre a mudança e a permanência. "Por isso", diz Freire, "a radicalidade é serena, na medida em que não teme mudar quando for necessário. [...] 0 radical está a serviço da verdade; o sectário de sua verdade, que ainda pretende impor" (Freire, 1995a, p. 66).

O século XX, do qual Paulo Freire faz parte com sua experiência que se iniciou num projeto de alfabetização de adultos em Angicos (Rio Grande do Norte), começa a revelar-se diante de nossos olhos como um rico manancial de experiências sociais 
e pedagógicas, inscritas em sonhos e projetos, que podem ser adjetivados como radicais. Myles Horton (Freire; Horton, 2003), no Centro Highlander, formou lideranças para o movimento de direitos civis nos Estados Unidos. James Coady (1939), articulando a educação com a economia, lançou as bases para um movimento de educação de adultos ligado à formação para o trabalho cooperativado, que se espalhou para muito além do Canadá. Ivan Illich (1972) propôs nada menos que o ousado projeto de acabar com a escola, tal como a conhecemos, por vê-la como fator constitutivo dos problemas das sociedades modernas. São propostas que talvez ajudem a situar-nos diante de um consenso pedagógico que parece sugerir o fim da própria pedagogia. Os problemas da educação são cada vez mais tratados como dificuldades pontuais de ampliação de cursos e melhora do nível de eficiência, quando não como questão de defasagem no uso das novas tecnologias. Os resultados de avaliações nacionais e internacionais tendem a adquirir um valor em si mesmos, não por último, como possibilidade de "agregar valor" econômico e de status social aos títulos conferidos.

A radicalidade, no sentido freireano, implica "trânsito", que é mais do que simples mudança. "E se todo Trânsito é mudança, nem toda mudança é Trânsito. As mudanças se processam numa mesma unidade de tempo histórico qualitativamente invariável, sem afetá-la profundamente.” (Freire, 1980, p. 46). Já o trânsito implica confrontar-se com temas novos e com novas tarefas, que são difíceis de identificar nos atuais "tempos líquidos", quando a própria ideia de progresso deixou de significar um salto para frente, mas é entendido como um "esforço desesperado para se manter na corrida" (Bauman, 2007, p. 108).

A pedagogia radical é, portanto, contrária a uma pedagogia do medo que insiste em agarrar-se a verdades que, por sua vez, geram os fundamentalismos que, hoje, podem ser encontrados em todas as áreas da vida, desde a religião até a própria pedagogia. ${ }^{4}$ Da mesma forma, ela se opõe a uma assunção acrítica de modismos. A radicalidade questiona as verdades não para encontrar uma verdade definitiva, mas por saber que o ser humano se realiza exatamente na busca do "ser mais".

\section{0 diálogo e a leitura do mundo}

Para Paulo Freire, o diálogo não pode ser confundido com uma técnica ou com um método pedagógico. Diálogo é, antes de tudo, uma maneira de ser, um modo de se relacionar com o mundo e com os outros. Não se pode optar pelo diálogo numa aula ou num de- 
terminado programa como uma proposta ou um projeto isolado. "A dialogicidade é uma exigência da natureza humana e também um reclamo da opção democrática do educador". (Freire, 1995a, p. 74).

A natureza humana caracteriza-se pelo inacabamento e, sobretudo, pela possibilidade de saber que se é inacabado. A educação, especificidade humana, funda-se sobre essa inconclusão que, ao mesmo tempo, a torna uma tarefa constante. Não há, segundo Paulo Freire, uma natureza humana preexistente, mas ela própria se constitui na história. Com suas palavras: "Tenho chamado a atenção para a natureza humana constituindo-se social e historicamente e não como um a priori” (Freire, 1995a, p. 75, grifo do autor). E isso é sempre um processo intersubjetivo, na medida em que o "ser mais" não existe à parte do "ser com".

O diálogo, no entanto, não acaba em si mesmo. Na medida em que ele busca a palavra autêntica, ele tem um caráter transformador da realidade. 0 próprio processo pedagógico é sempre revestido de diretividade, e o diálogo se coloca como condição e como meio para duas questões centrais no processo de ensinar e aprender.

A primeira delas é que o diálogo tem um caráter "desvelador" da realidade como encontro de pessoas para ouvir a palavra do outro e dizer a sua palavra. A leitura de mundo, que, na teoria freireana, precede a leitura da palavra, é uma tarefa permanente do educador, para a sua autoformação e para a formação de seus educandos. É uma leitura de mundo que, obviamente, vai além da informação sobre acidentes de trânsito, das notícias sobre o consumo de drogas e da violência. Trata-se da interpretação dessas informações, para a qual é importante contar com a ajuda de profissionais de várias áreas. Veja-se, por exemplo, que, ao levantar o universo vocabular em suas experiências de alfabetização, Paulo Freire contava com a colaboração de uma equipe interdisciplinar.

A leitura do mundo é tão importante porque tem a ver diretamente com as possibilidades que se percebem no sentido de transformação da realidade e, eventualmente, de criação de uma realidade diferente. Qualquer projeto novo ou alternativo de sociedade só será viável, se partir da visão clara daquilo que existe e se conseguir ver nas dificuldades o que Freire chama de situações-limite. Ou seja, as possibilidades emergem dos próprios obstáculos, quando vistos como produtos históricos e não como obras do destino.

O diálogo, como princípio metodológico, também fundamenta a imagem que Paulo Freire faz do educador como testemunha. Como ele escreve em Professora sim, tia não: 
Considero o testemunho como um "discurso" coerente e permanente da educadora progressista. Tentarei pensar o testemunho como a melhor maneira de chamar a atenção do educando para a validade do que se propõe, para 0 acerto do que valora, para a firmeza na luta, na busca da superação das dificuldades. A prática educativa em que inexiste a relação coerente entre o que a educadora diz e o que ela faz é, enquanto prática educativa, um desastre. (Freire, 1993, p. 75, grifos do autor).

Seu testemunho diz respeito à coerência entre o que ele diz e faz, à sua disponibilidade na luta pela justiça, pela liberdade e outros valores humanos. 0 testemunho tem a ver com a consciência da não neutralidade diante da vida que gosta de si e que está ameaçada. Em suas Cartas pedagógicas (Pedagogia da indignação), fala aos pais do tipo de testemunho diante das opções políticas e religiosas. Não se trata nem de omitir as opções nem de fazer com que sejam imitadas. "O que me cabe é testemunhar-lhes minha profunda amorosidade pela liberdade, meu respeito aos limites sem os quais minha liberdade fenece, meu acatamento à sua liberdade em aprendizagem para que eles e elas, amanhã, a usem plenamente no domínio político tanto quanto no da fé” (Freire, 2000, p. 37). O testemunho permite esse espaço de liberdade para a reinvenção do objeto do testemunho, tanto de quem escuta quanto de quem fala.

No caso dos professores, trata-se, também, sempre do testemunho no processo de conhecer-aprender-ensinar: ao ensinar, o professor ou a professora refaz, com seus alunos e diante deles, o ato de aprender e, com isso, ensina não só um conteúdo, mas a própria maneira de elaborar esse conteúdo. Dessa forma também não pode haver dicotomia entre o momento de "preparar" determinado conteúdo e o de, em seguida, "dar” este conteúdo numa aula. O caráter testemunhal evita, além disso, cair em duas posturas que, do ponto de vista pedagógico, são igualmente questionáveis: por um lado, o autoritarismo ou moralismo de quem sabe e acha que todos devem saber o que sabe e da forma como sabe; ou então o espontaneísmo que implica um ir e vir inconsequentes.

Na teoria de Paulo Freire, conhecimento é o resultado (nunca acabado) do ato de conhecer, ou seja, de um processo que envolve sujeitos ativos em torno de uma realidade também sempre dinâmica, porque é construída por intermédio das várias leituras que dela se fazem (Streck, 2012). Conhecimentos não são pacotes a serem passados adiante - não importa se via quadro negro, lâminas de retro- 
projetor ou power point -, mas apreensões da realidade que se realizam numa situação de conhecimento marcada pela densidade humana, de amor, de fé e de esperança. Enfim, o diálogo.

\section{Uma nova rigorosidade}

Uma das questões mais polêmicas na obra de Paulo Freire é a questão da rigorosidade. Que ele tem plena consciência disso se revela nas frequentes referências diretas a esse tema, sinalizando rupturas com um tipo de rigorosidade que precisa ser superado. Para ele, a rigorosidade vem sempre situada no contexto da politicidade e da eticidade. De nada vale o rigor, se ele estiver a serviço da dominação, talvez a tornando mais eficiente. Rigorosidade tem a ver com o desenvolvimento da capacidade crítica, com a assunção da vida como projeto, com a universalização da possibilidade de "ser mais".

Em outro sentido, a rigorosidade, em Paulo Freire, coloca como foco de atenção não uma teoria que precise ser compreendida pelo valor que tem em si, mas uma situação-limite que se vai constituindo como objeto da "curiosidade epistemológica" e da "rigorosidade metodológica" de educadores e educandos. Ele testemunha isso na sua forma de trabalhar questões que lhe são colocadas. Primeiro, o tema é tornado manejável. Assim como o jogador de futebol, ao receber a bola, procura torná-la “redonda” para prosseguir a jogada, Paulo Freire acerca-se ou aproxima-se amorosamente do tema. $\mathrm{O}$ objeto não é um inimigo que precisa ser vencido, mas um desafio com o qual se trava uma luta, ao mesmo tempo, dura e prazerosa. A aproximação é então feita por vários ângulos, num exercício provavelmente mais transdisciplinar do que interdisciplinar, uma vez que as fronteiras entre disciplinas são de menor importância. A lógica não é mais a das disciplinas que exigem uma aplicação rigorosa do método ou da curiosidade, mas é a própria situação-limite transformada em objeto de conhecimento que exige todo o rigor possível, inclusive aquele das disciplinas, quando necessário. Em outras palavras, Paulo Freire propõe uma recolocação da relação entre meios e fins, libertando da prisão aos meios, quando esses se transformam em fim e, com isso, muitas vezes em obstáculos para a compreensão da realidade, e libertando, sobretudo, para uma relação curiosa com o mundo.

Paulo Freire é um pensador que não teme atravessar fronteiras epistemológicas para compreender o mundo e traduzir a sua prática. Sua obra maior, a Pedagogia do oprimido, é permeada das fontes clássicas do pensamento ocidental, como Hegel, 
Marx, Fromm, Husserl, Sartre e outros. É deles que Paulo Freire deriva elementos-chave para a estruturação de sua obra: a visão de história, de sociedade, de homem e mulher, de opressão e libertação. Mas há também referências de Che Guevara e Fidel Castro, de Lenin e Mao Tsé Tung, assim como há a presença do discurso de descolonização por meio das obras de Franz Fanon e Albert Memmi. Entre os autores brasileiros citados, estão nomes como Antônio Cândido Mendes, Álvaro Vieira Pinto e Ernani Maria Fiori.

Todas essas fontes, no entanto, estão em permanente diálogo com o saber que brota da experiência, e não é raro Paulo Freire citar o pensamento de um agricultor ou de um operário ao lado do discurso de um intelectual. A legitimidade de uma fonte não provém do grau acadêmico de determinado autor, mas de seu potencial de incidência sobre a práxis transformadora. Não é a academia que legitima o saber popular, nem tampouco o inverso. Ambos os saberes são testados, legitimados e transformados na medida em que estão (ou não estão) a serviço de homens e mulheres que assumem seu papel de sujeitos.

0 resultado dessa forma de fazer pedagogia parece que nos autoriza a ver na pedagogia de Freire uma tentativa de libertação da pedagogia. ${ }^{5}$ Paulo Freire não apenas explicita uma nova pedagogia, mas, sobretudo, nos ensina uma nova maneira de fazer pedagogia. Richard Shaull, em 1972, no prefácio à edição inglesa de Pedagogia do oprimido, já comentava esse fato:

Ao longo dos anos, ele tem se engajado num processo de estudo e reflexão que tem produzido algo bastante novo e criativo em filosofia da educação. De uma situação de engajamento direto na luta por libertar homens e mulheres para criar um mundo novo, ele tem se valido do pensamento e da experiência daqueles em muitas situações diferentes e de posições filosóficas diversas. [...] Ele tem feito uso dos insights desses homens para desenvolver uma perspectiva de educação que é autenticamente sua e que procura responder à realidade concreta da América Latina (Shaull, 1972, p. 11).

É uma reflexão que implica a libertação de uma pedagogia supostamente neutra e universal para uma pedagogia do outro. Sob o manto do universalismo, a pedagogia moderna esconde a sua parcialidade a favor dos dominadores, o que não significa que não tivesse 
havido preocupação com as desigualdades e com a exclusão social. Na história da educação há muitas pessoas e instituições que, movidas pela caridade ou pela denúncia das injustiças e desigualdades sociais, fizeram da educação dos oprimidos a sua vocação. O novo, com Paulo Freire, é o fato de que eles, pela primeira vez, se tornam sujeitos da pedagogia. É uma pedagogia do oprimido e não para o oprimido. Talvez ninguém tenha dito isso melhor do que Ernani Maria Fiori, no prefácio à Pedagogia do oprimido, onde escreve:

Os métodos da opressão não podem, contraditoriamente, servir à libertação. Nessas sociedades, governadas pelos interesses de grupos, classes e nações dominantes, a "educação como prática da liberdade" postula, necessariamente, uma "pedagogia do oprimido". Não pedagogia para ele, mas dele (Fiori, 1981, p. 3, grifos do autor).

A pedagogia é libertada do universalismo neutro, que esconde ou naturaliza as muitas formas de dominação para reinventar-se a partir do outro.

\section{Conclusão}

O pensamento pedagógico contemporâneo se apresenta como um mosaico, no qual encontramos uma grande diversidade de teorias que convivem sob uma espécie de consenso pedagógico, ditado pelas necessidades de um mercado exigente e excludente. Entre os discursos, encontramos o construtivismo, a teoria sistêmica, o pós-estruturalismo, a pedagogia das competências, a pedagogia crítica e as várias correntes que estudam os usos e as implicações das tecnologias digitais. A preocupação maior, no entanto, está centrada pragmaticamente em aprender como aprender, de preferência por toda a vida, e com a utilização das novas tecnologias digitais.

Nesse contexto, Paulo Freire representa dois papéis aparentemente contraditórios, mas, na realidade, complementares. Por um lado, seu pensamento é conectivo, articulando diferentes posições e não temendo o trabalho nas fronteiras das áreas de conhecimento e nas perspectivas epistemológicas na busca de uma educação para que as pessoas não se sintam exiladas de seu tempo. Brandão (2010, p. 42) fala de sua "vocação coerentemente errante e andarilha", já nos tempos de Angicos: “Em tempos em que pessoas, grupos de militantes e movimentos sociais não raro reduziam o olhar de suas ideias a alguns poucos autores de uma única teoria social, Paulo 
Freire foi sempre um tecelão das diferenças". Também hoje a adesão a certos cânones teóricos sugere podermos prescindir do esforço de "pensar certo" que, para Paulo Freire, estava vinculado com a reflexão metódica sobre a prática com o concurso das ferramentas que melhor dessem conta de compreender a realidade. Foi assim, conforme seu depoimento (Freire, 1997), que uma certa camaradagem com Cristo o levou para os mangues e as favelas do Recife, mas, chegando lá, precisou de Marx para explicar as condições de vida do povo.

Por outro lado, ele não dispensa buscar as "raízes" e compreender as condições sociais nas quais as práticas educativas estão inseridas, a partir do pressuposto de que a educação não pode ser resumida a práticas de adaptação ao mundo, mas deve criar condições para a emergência dos "inéditos viáveis". Em tempos de mudanças rápidas, quando o chão debaixo dos pés parece sumir, o exercício de pensar a educação de uma forma, ao mesmo tempo larga e profunda (Streck, 2011), é um imperativo para a pedagogia. Com o desenvolvimento da pesquisa no âmbito da educação brasileira nas últimas décadas, não basta buscar articular teoria e prática no âmbito da abstração, é preciso fazer da prática o lugar da teoria. 


\section{Referências bibliográficas}

ANDREOLA, Balduíno. Carta-prefácio a Paulo Freire. In: FREIRE, Paulo. Pedagogia da indignação: cartas pedagógicas e outros escritos. São Paulo: Editora UNESP, 2000.

ARAÚJO FREIRE, Ana Maria (Org.). A pedagogia da libertação em Paulo Freire. São Paulo: Editora UNESP, 2001.

BAUMAN, Zygmunt. Tempos líquidos. Rio de Janeiro: Zahar, 2007.

BOFF, Leonardo. Transcendência. In: STRECK, Danilo R.; REDIN, Euclides; ZITKOSKI, Jaime José. (Org.). Dicionário Paulo Freire. 2. ed. Belo Horizonte: Autêntica, 2010. p. 407-408.

BRANDÃO, Carlos Rodrigues. Andarilhagen. In: STRECK, Danilo R.; REDIN, Euclides; ZITKOSKI, Jaime José. Dicionário Paulo Freire. 2. ed.. Belo Horizonte: Autêntica, 2010.

CALLONI, Humberto. Ecologia. In: STRECK, Danilo R.; REDIN, Euclides; ZITKOSKI, Jaime José (Org.). Dicionário Paulo Freire. 2. ed. Belo Horizonte: Autêntica, 2010. p. 131-133.

COADY, James. Masters of their own destiny. New York; London: Harper \& Row, 1939.

FIORI, Ernani Maria. Aprender a dizer a sua palavra. In: Pedagogia do oprimido. 9. ed. Rio de Janeiro: Paz e Terra, 1981.

FREIRE, Paulo. À sombra desta mangueira. São Paulo: Olho d’Água, 1995 a.

FREIRE, Paulo. Cartas a Cristina. Rio de Janeiro: Paz e Terra, 1994.

FREIRE, Paulo. Educação como prática da liberdade. 11. ed. Rio de Janeiro: Paz e Terra, 1980.

FREIRE, Paulo. Entrevista. Entrevistadora: Luciana Burlamaqui. TV PUC/SP, 17 abr. 1997. 1 DVD.

FREIRE, Paulo. Pedagogia da autonomia: saberes necessários à prática educativa. São Paulo: Paz e Terra, 1996.

FREIRE, Paulo. Pedagogia da esperança: um reencontro com a Pedagogia do oprimido. Rio de Janeiro: Paz e Terra, 1992.

FREIRE, Paulo. Pedagogia da indignação: cartas pedagógicas e outros escritos. São Paulo: Editora UNESP, 2000.

FREIRE, Paulo. Pedagogia do oprimido. 9. ed. Rio de Janeiro: Paz e Terra, 1981.

FREIRE, Paulo. Política e educação. 2. ed. São Paulo: Cortez, 1995b. (Coleção Questões de nossa época, v. 23).

FREIRE, Paulo. Professora sim, tia não: cartas a quem ousa ensinar. São Paulo: Olho d’Água, 1993. 
FREIRE, Paulo; GUIMARÀES, Sérgio. Sobre educação (Diálogos). Rio de Janeiro: Paz e Terra, 1984. v. 2.

FREIRE, Paulo; HORTON, Myles. O caminho se faz caminhando: conversas sobre educação e mudança social. Petrópolis: Vozes, 2003.

GADOTTI, Moacir. Pedagogia da Terra. 2. ed. São Paulo: Peirópolis, 2000.

GALLO, Silvio; VEIGA-NETO, Alfredo (Org.). Fundamentalismo \& Educação. Belo Horizonte: Autêntica, 2009.

ILLICH, Ivan. Deschooling Society. New York: Harper \& Row, 1972.

SHAULL, Richard. Foreword. In: FREIRE, Paulo. Pedagogy of the oppressed. New York: Herder and Herder, 1972. p. 9-15.

STRECK, Danilo R. Cinco razões para dialogar com Paulo Freire. Revista E-curriculum, São Paulo, v. 7, n. 3, p. 1-19, dez. 2011.

STRECK, Danilo R. Pedagogia no encontro de tempos: ensaios inspirados em Paulo Freire. Petrópolis: Vozes, 2001.

STRECK, Danilo R. Qual o conhecimento que importa. Revista E-curriculum, São Paulo, v. 12, n. 3, p. 8-24, set/dez. 2012.

STRECK, Danilo R.; REDIN, Euclides; ZITKOSKI, Jaime José. (Org.). Dicionário Paulo Freire. 2. ed. Belo Horizonte: Autêntica, 2010.

STRECK, Danilo R.; REDIN, Euclides; ZITKOSKI, Jaime José. (Ed.). Paulo Freire Encyclopedia. Lanham: Rowman \& Littlefield, 2012.

TORRES NOVOA, Carlos Alberto. La práxis educativa de Paulo Freire. México: Gernika, 1977.

TORRES NOVOA, Carlos Alberto; NOGUERA, Pedro (Ed.). Social justice education for teachers: Paulo Freire and the possible dream. Rotterdam: Sense, 2008.

TORRES, Rosa Maria. Os múltiplos Paulo Freire. In: ARAÚJO FREIRE, Ana Maria (Org.). A pedagogia da libertação em Paulo Freire. São Paulo: Editora UNESP. 2001. p. 231242.

Submetido à avaliação em 24 de agosto de 2013.

Aprovado para publicação em 28 de agosto de 2014. 